\title{
Corrigendum to "Challenges in Interpretation of Thyroid Function Tests in Pregnant Women with Autoimmune Thyroid Disease"
}

\author{
Ulla Feldt-Rasmussen, ${ }^{1}$ Sofie Bliddal, ${ }^{1}$ Åse Krogh Rasmussen, ${ }^{1}$ Malene Boas, ${ }^{2}$ \\ Linda Hilsted, ${ }^{3}$ and Katharina Main ${ }^{2}$ \\ ${ }^{1}$ Department of Medical Endocrinology, Rigshospitalet, Blegdamsvej 9, 2100 Copenhagen, Denmark \\ ${ }^{2}$ Department of Growth and Reproduction, Rigshospitalet, Blegdamsvej 9, 2100 Copenhagen, Denmark \\ ${ }^{3}$ Department of Clinical Biochemistry, Rigshospitalet, Blegdamsvej 9, 2100 Copenhagen, Denmark \\ Correspondence should be addressed to Ulla Feldt-Rasmussen; ufeldt@rh.dk
}

Received 26 September 2017; Accepted 9 October 2017; Published 25 October 2017

Copyright (c) 2017 Ulla Feldt-Rasmussen et al. This is an open access article distributed under the Creative Commons Attribution License, which permits unrestricted use, distribution, and reproduction in any medium, provided the original work is properly cited.

In the article titled "Challenges in Interpretation of Thyroid Function Tests in Pregnant Women with Autoimmune Thyroid Disease" [1], the name of the second author was given incorrectly as Anne-Sofie Bliddal Mortensen. The author's name should have been written as Sofie Bliddal. The revised authors' list is shown above.

\section{References}

[1] U. Feldt-Rasmussen, A.-S. B. Mortensen, Å. K. Rasmussen, M. Boas, L. Hilsted, and K. Main, "Challenges in interpretation of thyroid function tests in pregnant women with autoimmune thyroid disease," Journal of Thyroid Research, vol. 2011, Article ID 598712, 7 pages, 2011. 


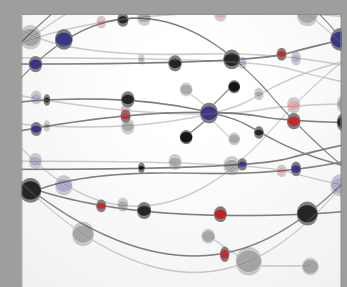

The Scientific World Journal
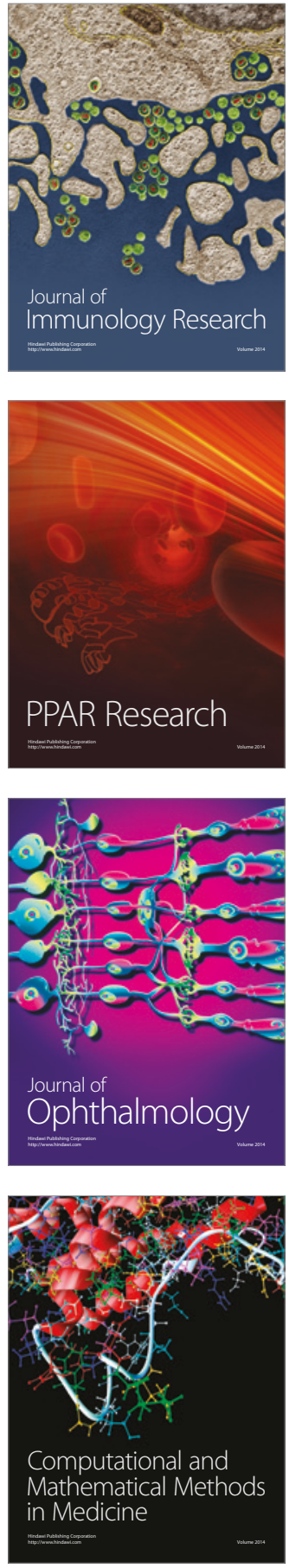

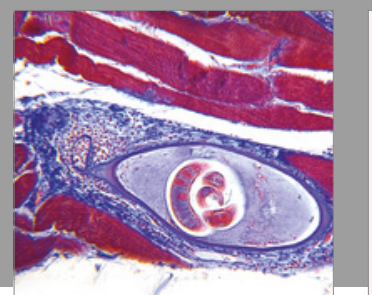

Gastroenterology Research and Practice
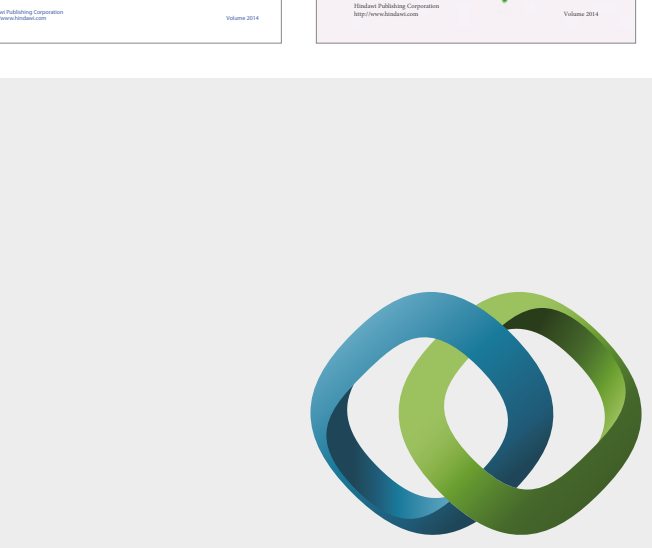

\section{Hindawi}

Submit your manuscripts at

https://www.hindawi.com
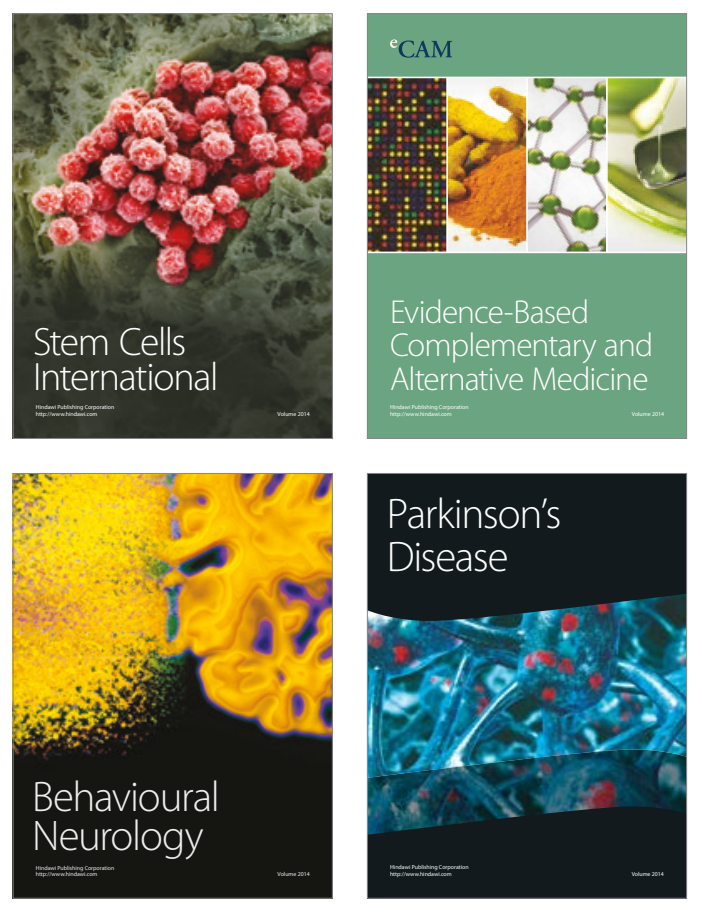
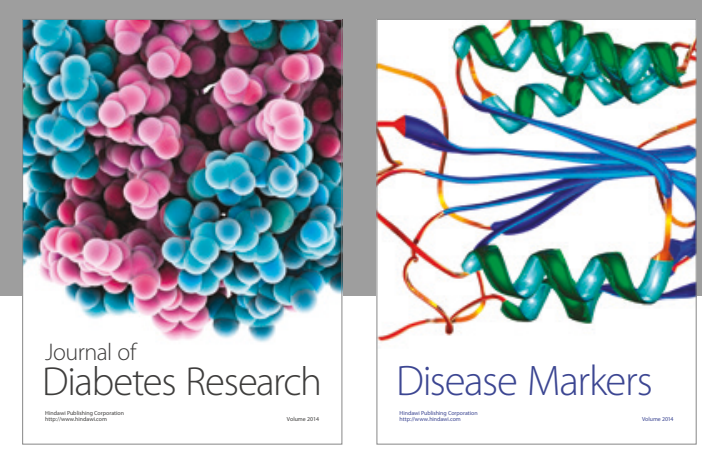

Disease Markers
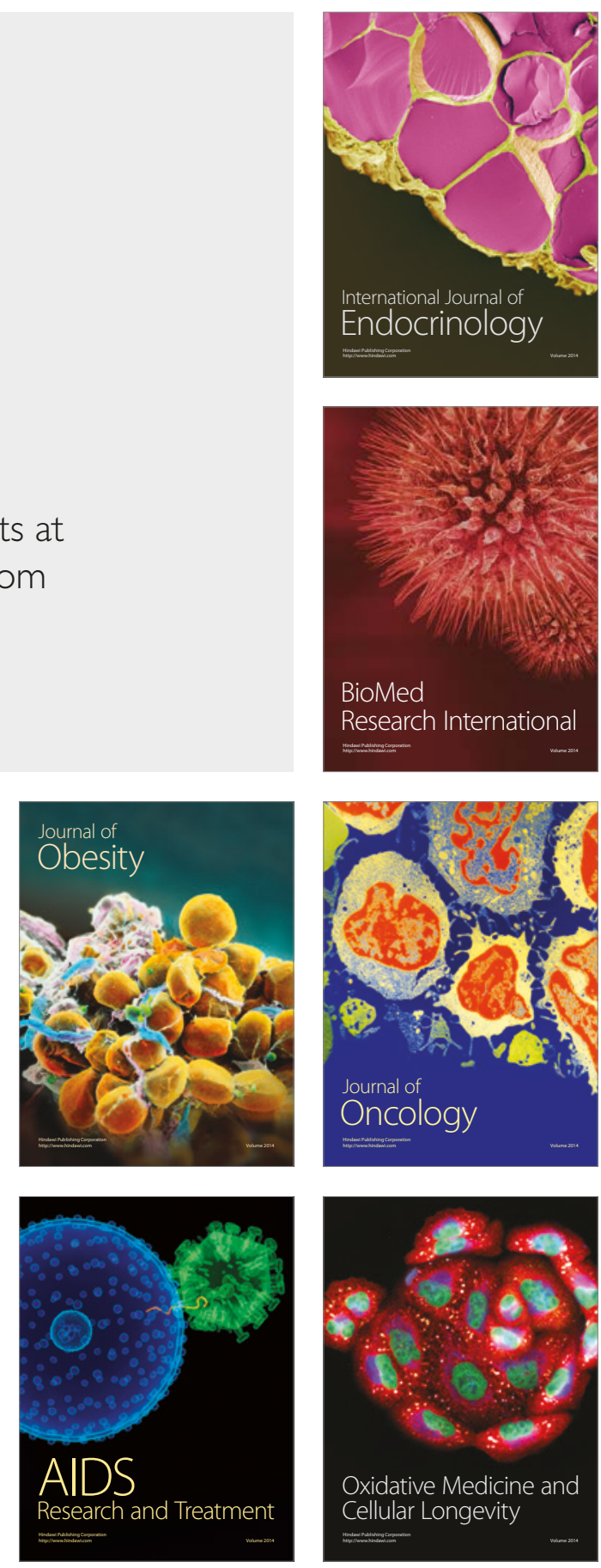